\title{
Work in progress: Development and use of an active learning classroom for a course on Dynamic Systems
}

\section{Dr. Tiina M. Komulainen, Oslo and Akershus University College}

Tiina M. Komulainen is associate professor in automation at Oslo and Akershus University College in Norway. She earned MSc and DrSc degrees in chemical engineering from Helsinki University of Technology, Finland. Dr. Komulainen has background in industrial process modeling and control. She has worked with dynamic process simulation of large scale industrial oil and gas processes at Kongsberg Oil \& Gas Technologies before joining Oslo and Akershus University College. Dr Komulainen has research interests in engineering education research, process simulators and chemical process modeling.

\section{Dr. Christine Lindstrøm, Oslo and Akershus University College}

Christine Lindstrøm works as an Associate Professor of Science in the Faculty of Teacher Education at Oslo and Akershus University College in Oslo, Norway, where she teaches physics and science education to pre-service science teachers. She undertook her tertiary studies at the University of Sydney, Australia, from which she has a Bachelor of Science (Honours), Master of Education and PhD in Physics. Christine's $\mathrm{PhD}$ project was in Physics Education Research, where she focused on improving the first year physics course by developing and implementing 'Link Maps', as well as synthesising an understanding of physics student learning by integrating a variety of theoretical backgrounds, from neuroscience via cognitive psychology to educational theories. Christine's current research focuses on improving the science teacher education program at Oslo and Akershus University College, and she has a keen interest in how the brain learns physics. Christine also holds a position as Adjunct Associate Professor of University Pedagogy at the Norwegian University of Science and Technology, where she teaches short courses on university teaching to PhD students and researchers.

\section{Mr. Tengel Sandtrø, Oslo and Akershus University College}

Tengel Sandtrø is currently manager for the Educational Spaces-project at Oslo \& Akershus University College. He has worked with eduational technology and distance education since 2002. With a past as both lecturer (Oslo University College) and e-learning editor (Norwegian Medical Association), he has experienced the use and abuse of technology. As a project manager, he has been through the stages from the novelty of VLEs to embedding educational technology in classrooms of today - and tomorrow. He received a MA in Social Anthropology (2000) from Goldsmiths' College, University of London. 


\section{Development and use of an active learning classroom for a course on Dynamic Systems}

\section{Introduction}

Large-scale reviews in physics and STEM education research have consistently found that student active learning methods increase student learning outcomes and decrease drop-out rates $[1,2]$. Our motivation for testing active learning methods in a technology-rich environment was the student association's request for more active learning methods at our institution, and student feedback on course evaluations from fall 2013. The student feedback on a course in Dynamic Systems in 2013 was that it was good, but that it required "solid knowledge and skills in mathematics, physics and chemistry, thus the difficulty level is high". Students liked how four out of six hours of classes per week were spent on exercises, which "are very useful for learning", but "student assistants are needed for the exercises" as were "better suited exercise classrooms, (as there is) too little space now".

Our research questions were: 1) how to approach constructing the first Active Learning Classroom (ALC) in our tertiary institution?; 2) how to approach teaching an engineering course in an ALC when the instructor has no personal experience of active learning methods, or the education research such teaching methods are based on?; and 3) can we see a positive effect on student results after the first ALC trial?

This pilot project is a case study of a course in Dynamic Systems. It was taught by the same instructor during fall 2013 and fall 2014, using traditional lecturing and exercises in fall 2013 and active learning methods in fall 2014.

\section{Background}

\subsection{Pedagogy}

The positive effect of student active learning methods on learning is well documented, especially in the STEM (Science, Technology, Engineering, and Mathematics) disciplines ([3], [2], [1]). Two projects in which a student active pedagogy has been systematically and extensively integrated since around the year 2000 are SCALE-UP (Student-Centered Active Learning Environment for Undergraduate Programs) at North Carolina State University [4] and TEAL (Technology-Enabled Active Learning) at the Massachusetts Institute of Technology [5]. Both projects revolve around student active learning methods in rooms especially designed to foster group work and integrate technology with classroom activities. The success of these projects has spread the development and use of such Active Learning Classrooms (ALCs) not only in the US, such as at the University of Minnesota, but also to countries on other continents, such as Taiwan [6].

Because activities in an ALC focus more on group work than on traditional instruction, it is generally implemented in conjunction with a Flipped Classroom (FC) pedagogy. FC refers to a teaching methodology where students are required to have their first exposure to the subject material at home prior to class, and where class time is spent working with the material [7]. To increase compliance with pre-work completion and to give the instructor an insight into what the students have understood prior to class, FC is often combined with a Just-in-Time Teaching (JiTT) methodology, in which students complete an online quiz prior to class [8]. This provides feedback that enables the instructor to tailor the class activities to the particular student group.

ALCs have been documented to improve the outcome for some groups of students more than others. Lasry et al. [9] found that students with medium prior knowledge benefited far more from active learning compared to traditional pedagogy than students with high prior knowledge. 
Walker et al. [10] report similar findings for an active learning pedagogy in an ALC; students with low ACT scores benefited more from the ALC than students with high ACT scores.

\subsection{Space and technology}

Space and furnishing alone do not increase learning [11]; However, Cotner et al. [12] found that in an active learning classroom (ALC), time spent on lecturing decreased, while time spent on consulting and leading group activities increased when the same lecturer used the same activities in an ALC compared to a traditional classroom. In addition, the students in the ALC felt more engaged and grades were higher than in the traditional classroom. Controlled for differences in American College Testing (ACT) scores, the grades were half a letter grade better than expected in the course taught in the ALC [12]. The ACT is a college readiness assessment, a standardized test for high school achievement and college admissions in the United States.

When designing an ALC, the Pedagogy-Space-Technology (PST) Design \& Evaluation Framework is a helpful tool in guiding the process. PST is a question-based framework that originated in the Australian "Next Generation Learning Spaces" project (NGLS). The NGLS had a wider perspective than classrooms, and included libraries and other areas where students study, encompassing both informal and formal settings. The framework has been developed by Radcliffe [13] "to aid diverse stakeholders to approach the creation, operation and evaluation of new learning spaces". The PST model facilitates the design of an ALC by structuring the process into distinct dimensions and stages, and offering guiding questions for each stage. The dimensions are pedagogy, space, and technology, and the relevant stages are design and operation. For instance, a guiding question for the classroom design stage is "what is the overall focus (of the space) and what type(s) of learning and teaching are we trying to foster (in this space)?"

\section{Context}

This pilot study was conducted at a large teaching-focused tertiary institution in Norway, which has a long history of engineering education. The institution currently offers eight different bachelor's level programs in engineering and four master's level programs in engineering. The research in engineering mainly focuses on ICT (information and communication technology) solutions and civil engineering, in addition to some engineering education research.

The new active learning space, called ProLab, was used in a course on Dynamic Systems. The course corresponds to one-third of a full semester load for the students. The course lasts for 14 weeks (the whole teaching semester), and is offered to second year students in the electrical engineering degree program majoring in Automation. The course covers modeling and analysis of first and second order dynamic systems in the time and frequency domain, with application to the oil and gas industry. The course has one instructor, two Learning Assistants (third year engineering students who completed the course in their second year) and one laboratory engineer. The expected course commitment from students is 13 hours per week: pre-class preparation including reading, numerical tasks and online quizzes (2-3 hours/week), classes with active learning methods $(2.45 \mathrm{~min}$ on Mondays and $4.45 \mathrm{~min}$ on Tuesdays, a total of 6 teaching hours in ProLab per week), laboratory sessions (3-4 hours fortnightly), and compulsory assignments (3-4 hours fortnightly). All assignments must be satisfactorily completed for students to be allowed to sit the final examination, which counts for $100 \%$ of the course grade.

Students who fail the end-of-semester final examination are entitled to take a resit-examination three months later. If they pass the resit-examination, there will be no record of their original fail grade. Consequently, some students deliberately submit a blank paper in the end-ofsemester examination in order to take the resit-examination, which gives them more time to 
prepare for each examination. Hence, the examination results for each cohort are final only after the resit-examination.

\section{Design and use of Prolab}

The design of the ProLab classroom was inspired by SCALE-UP [14], TEAL [15] and Active Learning Classrooms [10]. Although there are general guidelines for the design and construction of an ALC (Colleges, 2010), there are also local constraints when an existing room is converted into an ALC. The PST framework, which has been successfully implemented at the University of Queensland [16], was used to structure and guide the ProLab design process. We discuss the design stage and the operation stage for each of the three dimensions pedagogy, space, and technology.

\subsection{Space}

The intention of the design of the ProLab space was to promote active and group-oriented learning, even if building such a space rendered it unsuitable for traditional lecturing. The room made available for conversion into ProLab was rather long and narrow (floor area of around $110 \mathrm{~m}^{2}$ ), which made it less than ideal for a traditional classroom because the back of the room was too far from the podium. Some of the intended flexibility of the space had to be sacrificed to reduce cost: we were unable to set the room up with tables that could be reconfigured for different group sizes, with the result that ProLab accommodates 64 students in a room with eight rectangular group tables, which seat four students on each long side (see Figure 1). Each group table has a small screen and web-conference equipment at one end of the table. The instructor has a table with a PC and a Sympodium writable screen, and a control panel for five large screens. A tablet with the same functionality as the control panel is also available, which offers the instructor the flexibility to move around. The room has five large screens placed 1.5 meter up the walls to be visible to everyone in the room (see Figure 2).

The operation of ProLab has largely functioned according to its design. The group tables have worked well. Each group consists of two tables, where one table can be moved, thus enabling group sizes of between three and eight students. There have been some issues with ventilation however. The space was originally used for drama classes, and the ventilation system was designed for about 12 students. Increasing the number of students to 60 without changing the ventilation system was the biggest problem with the space itself. 


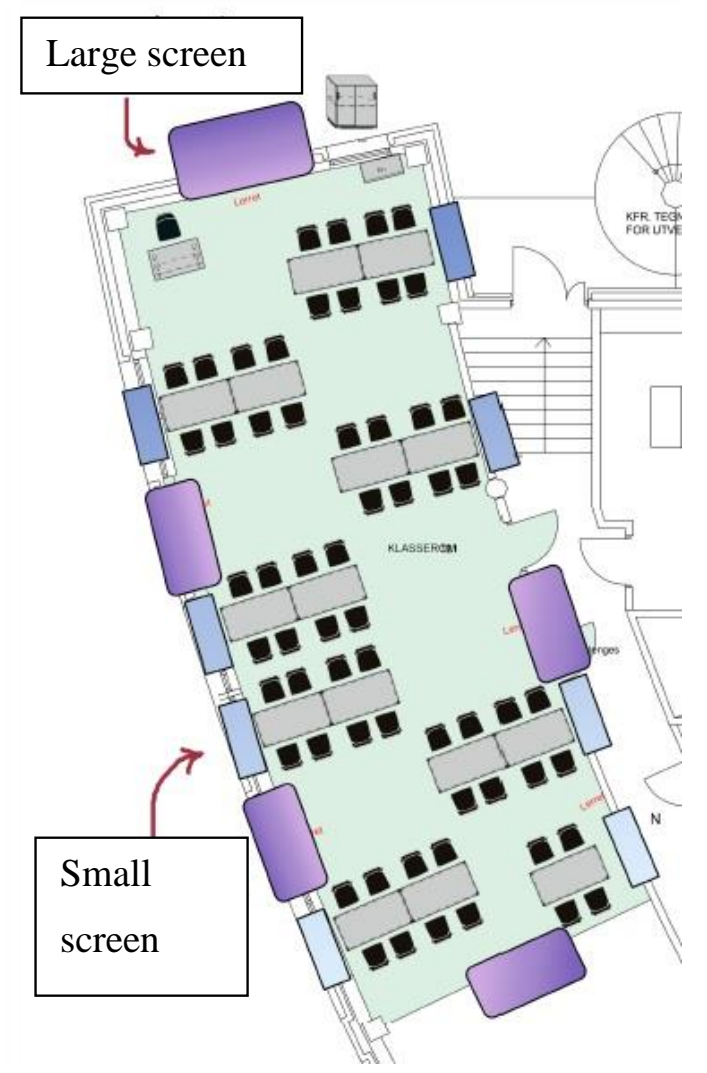

Figure 1: Illustration of ProLab with its eight group tables each with a small screen at the end of the table, the instructor's table, and five large screens on the walls for plenary presentations.

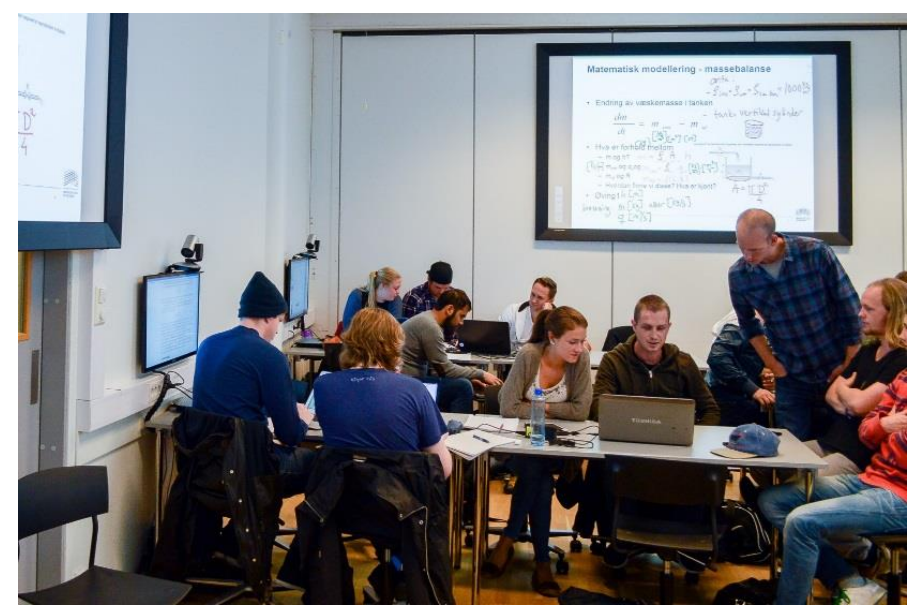

Figure 2: A view from the door in the middle of the room towards the back end of the room. Students present their tasks on the small screens at the end of each table. The large screens can display the instructor's slides as well as mirror the smaller student screens (using Crestron Airmedia software).

\subsection{Technology}

The large screens can be controlled wirelessly via Crestron Airmedia screen sharing software, which enables students to present tasks on the large screens in addition to the small screens. Students are responsible for bringing their own laptops or tablets, and for installing necessary software such as Matlab (with university/ student license) and Crestron Airmedia. Students connect to the group's shared screen through a cable provided at the table. In the Dynamic Systems class, students were introduced to the technology in the first session. After this 
introduction, the students and the instructor experienced no particular issues with technology. The students were used to group work and had the technical knowledge to work independently in a room on the basis of a "bring your own device" solution.

\subsection{Pedagogy}

The instructor was an Associate Professor with no previous experience of active learning methods. The pedagogical design of the Dynamic Systems course was therefore developed in collaboration with an Associate Professor of Science Teacher Education with nine years' experience as a Physics Education Researcher (the second author). The idea for the pedagogical design in ProLab was to implement a blended learning model where students would work on the easier theoretical aspects of the curriculum at home prior to class, leaving more complex theory and problem solving to be worked on in groups in the ProLab with the help of the instructor and the Learning Assistants (flipped classroom and blended learning). The individual pre-work comprised online-quizzes, which required the reading of new theory and the completion of simple numerical exercises. In addition, every quiz included questions about theoretical matters or calculations that the students wanted the instructor to explain at the beginning of the ProLab sessions (Just-In-Time-Teaching).

The ProLab classes aimed to cover advanced theory (especially the modeling of different kinds of chemical reactors), theoretical exercises, and simulation exercises in groups of three to four students. The activities designed for the ProLab classes comprised a short lecture or demonstration of a modeling technique or a calculation example by the instructor, group work on theoretical/ analytical/ simulation exercises, student presentations in the groups using the small screens, group discussions, and students' plenary presentations on the large screens. Every ProLab session concluded with students giving a short plenary presentation of the exercise results using the large screens, and the instructor summarizing the lesson. Every second week, the students were given an individual twenty-minute theory mini-test, which they had to peer mark afterwards in order to get fast feedback. The topic of the mini-tests was the modeling of different kinds of chemical reactor tanks and analysis of the identified transfer function, corresponding to the theory of the past two lessons. Every second week, the students were also required to work (in groups) on a larger compulsory assignment combining modeling and simulation exercises.

An important aspect of ProLab was to enhance group work and presentation skills. The students were used to group work from previous courses. In the laboratories in particular, students carry out experiments and submit lab reports jointly in groups of two students. In the Dynamic Systems course, the students were grouped based on their academic records, i.e., every group would have one A/B student, one or two $\mathrm{C}$ students and one D/E student, determined as their average mark from the Physics and Chemistry course. The setting in ProLab enabled the students to work effectively in groups and to present their work to their own group (small screens) and to the whole class (large screens). The physical design of ProLab enabled a high degree of flexibility and allowed rapid transition between different activities. The students are activated by inclusion, as group members solving tasks, and as presenters for their class. The pre-class activities were designed on an individual basis, whereas the ProLab activities, laboratory exercises, and homework assignments were designed for groups of two to four students.

Based on the pedagogical design, the instructor had to completely redesign the detailed lecture/exercise plans for each week. The instructor's theory presentations had to be modified quite drastically from the lecture slides for traditional classroom lectures to material supporting

active learning. The theoretical material was divided into three categories: simple enough for students' self-study and quizzes prior to ProLab-sessions, theory/modeling technique 
presentations with short theory tasks for the groups to work on in ProLab prior to numerical exercises, and material to be discarded due to time limits. The exercise material from last semester could be reused with minor modifications. There were enough analytical, numerical, modeling, and simulation exercises, so that the groups could work on different tasks making the plenary presentations more interesting.

The instructor's role in ProLab was as a facilitator for active learning in groups, group work on theoretical and practical exercises, and small group/plenary presentations. Together with the instructor, the Learning Assistants had an important role in making sure that all groups were able to proceed with their exercises, i.e., providing theoretical and practical assistance with the tasks so that the groups did not get stuck and lose valuable time in ProLab.

The operation of ProLab worked largely in accordance with its pedagogical design. The biggest obstacle was the significant level of student non-compliance with the pre-work. On average, $54 \%$ of the students did not do the pre-class quizzes, and were thus presumed to lack the theoretical background for each session. As a consequence, the instructor chose to spend more time lecturing theory and demonstrating simple numerical exercises than originally intended. Another obstacle was grouping students at the beginning of the semester, because the enrolment list was not finalized until one month after the semester started. Some new students enrolled three weeks into the semester whereas others dropped out after realizing they did not have the prerequisites for the course.

The instructor kept a log of classroom activities at ten-minute intervals. As illustrated in Figure 3 , class time included multiple student-centered activities as well as lecturing and demos by the instructor. "Group work and plenary discussion" included group work on conceptual questions and presentation of the results of the exercises. "Students: Pen and paper exercise" included group and individual work on theoretical exercises without numerical answers. "Students: Matlab/K-Spice exercise" included group and individual problem solving using simulation tools. "Mini-test" included time used for individual, bi-weekly mini-tests on theoretical and numerical exercises. "Teacher demos" included instructor demonstrating solution to the minitests and to some of the theoretical exercises. "Lecturing" was traditional theory lecturing. "Other teacher-centered" included formal course information that was not related to learning. "Technical setup" was the time used to install and test the Crestron Airmedia software for plenum presentations on the large screens.

From the instructor's perspective, the implementation of active learning methods in ProLab was challenging but very rewarding. The instructor's previous, positive experience of exercisefocused classes was the inspiration for trying out active learning methods in ProLab. The instructor wished to use more industrially relevant exercises (simulation) and up-to-date platforms and technologies for the electrical engineering course. The instructor felt comfortable with the new, active form of teaching due to the detailed planning, pedagogical support, and encouraging students. The experience was highly positive: all the participants, including the instructor and the Learning Assistants, gained new knowledge, skills, and competencies, and the student feedback was mainly supportive and appreciative of the course structure and class activities. 


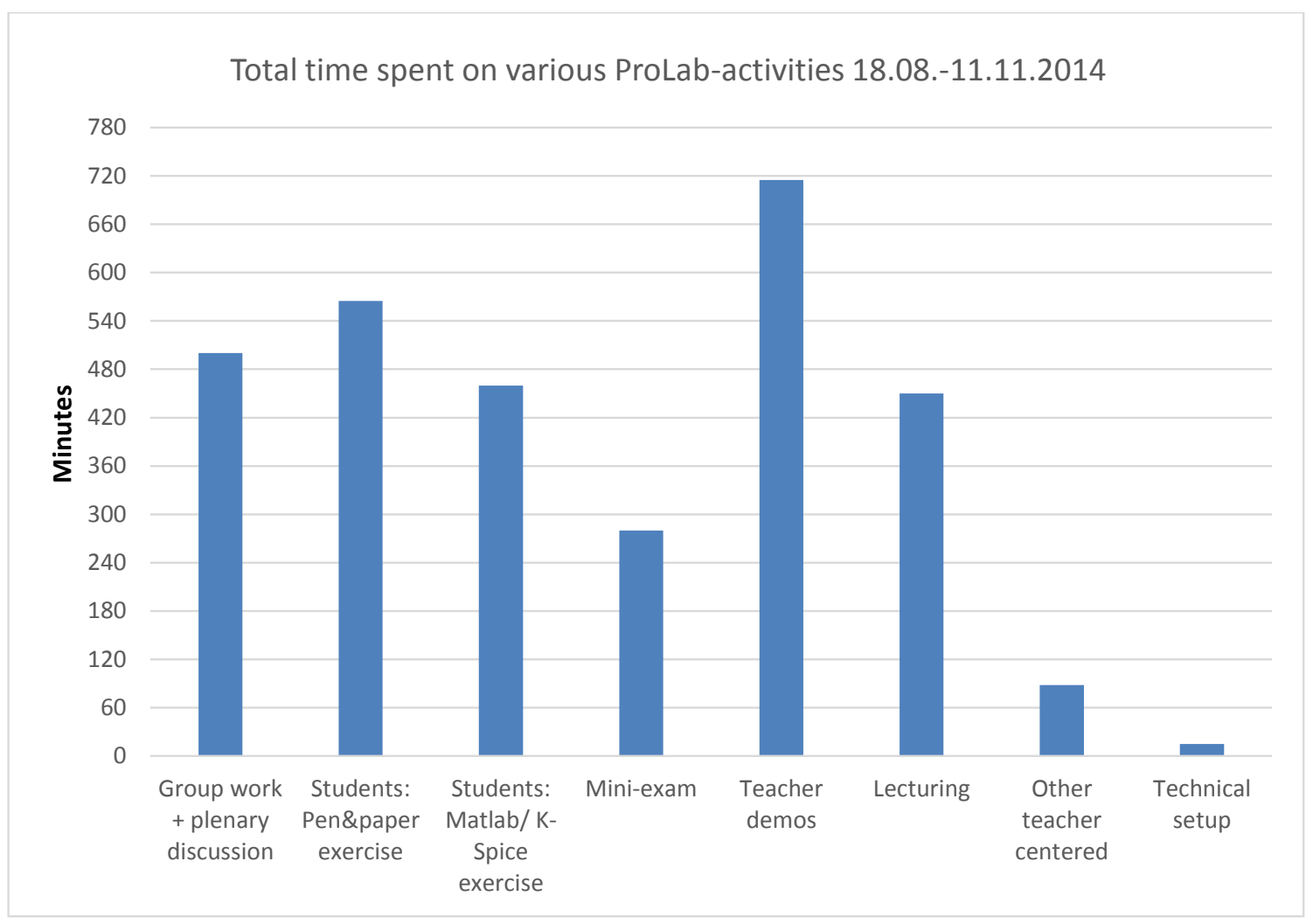

Figure 3: The instructor's activity log showing cumulative time on different course activities.

\section{Data collection}

The following data were collected to evaluate the Dynamic Systems course: a Control Systems Concept Inventory pre- and post-test [17], four bi-weekly mini-tests with peer evaluation, instructor's activity log (Figure 3), attendance, student course evaluations, and the end-ofsemester examination. The examination results (fall 2014) are compared to the corresponding results from fall 2013.

The Control Systems Concept Inventory developed by Bristow et al. [17] tests different aspects of and typical misconceptions in five central topics in control theory: system models, stability, time response, frequency response, and feedback. Only the first four topics were covered in the Dynamic Systems Course. The Concept Inventory consists of one open question and 18 multiple choice questions, each with five alternatives (four response alternatives plus "I don't know"). The open question on feedback control and five of the 18 multiple choice questions were not covered in the Dynamic Systems course. Hence, the expected maximum score was 13 out of 18 , corresponding to $72 \%$. However, the whole test was given to the Dynamic Systems students in order to allow comparison with the results of Bristow et al. [17]. Bristow et al. [17] gave the Control Systems Concept Inventory to two groups of students taking the same Control Systems course, which covered all the five central topics in control theory tested by the Concept Inventory.

The student course evaluation was conducted in collaboration with the student representatives in the middle of the semester and again at the end of the semester. The instructor wrote a course evaluation questionnaire, which was edited by the student representatives and administered via the electronic learning platform (Fronter) by the instructor. Students were instructed by email to complete the course evaluation within a week. The student representatives held a feedback 
session with the class to collect additional comments. The results of the questionnaire and the students' oral feedback were summarized by the instructor and the student representatives.

\section{Results}

\subsection{Attendance}

Forty-nine students were enrolled in the class. The percentage attendance throughout the semester is shown in Figure 4. Of a total of 23 ProLab classes, attendance was only recorded for 20 due to an instructor error (missing data 25.8.2014, 1.9.2014, 10.11.2014). The average course attendance was $72 \%$, which is considered quite successful. Attendance is generally not recorded for the electrical engineering courses, but, anecdotally, colleagues at the Department of Electrical Engineering quote typical course attendance of around $50 \%$ for this second year electrical engineering group. The sessions with nearly $100 \%$ attendance were compulsory: the first was an oil and gas process simulation exercise and the second a seminar session summarizing the learning outcomes from the simulation exercises.

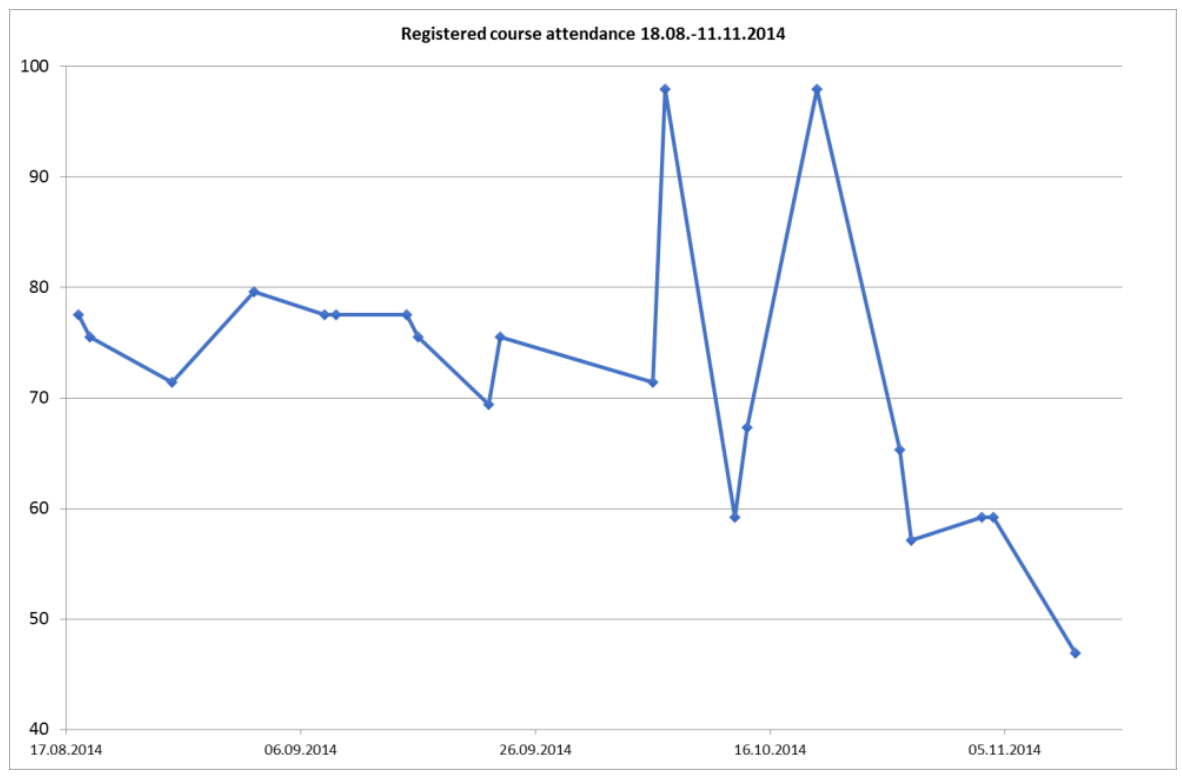

Figure 4: Percentage course attendance during fall semester 2014.

\subsection{Mini-test results}

The mini-test was given every second week to the students attending the Dynamic Systems course. About $80 \%$ of the students reported their scores in 2014, which were counted based on raised hands for five different percentage categories $(0-19 \%, 20-39 \%, 40-59 \%, 60-79 \%$, and $80-100 \%)$. The average result of each test was $39 \%-65 \%$, whereas the average result of each test in 2013 was $31 \%-56 \%$. The student representative explained that many of the students felt uncomfortable reporting their scores in public, and suggested using an anonymous voting tool to collect the scores instead of a hand-count. Due to the likely self-selection bias in selfreporting and inherent lower reliability of self-reports, the results were not of a sufficient quality that any clear conclusions could be drawn from them.

\subsection{Diagnostic test results}

A total of 43 of 49 students participated in the Control Systems Concept Inventory pre-test, but only 25 students attended the post-test. The pre- and post-test results (of the 18 multiple-choice questions) are presented in Table 1 for the 22 students who participated in both tests, to allow comparison with the results of Bristow et al. [17]. The normalized gain (also presented in Table 1 ) is the percentage of points obtained in the post-test that were not obtained in the pre-test [3]. 
However, given that not all the topics in the Concept Inventory were covered in the course, a gain of $100 \%$ was not a realistic maximum.

Bristow et al. [17] report results for two student groups in the same Control Systems course: mechanical engineering students $(N=63)$ and mechatronics students $(N=72)$. The mechanical engineering students improved their average score from $21.4 \%$ to $39.6 \%$, corresponding to a normalized gain of $23 \%$. This result is similar to our result. The mechatronics students, however, differed quite markedly: they had a much higher pre-test score at $30.0 \%$ and a posttest score of $53.5 \%$, resulting in a normalized gain of $34 \%$.

Table 1: The results of the Control Systems Concept Inventory pre- and post-tests for students in the Dynamic Systems Course Fall 2014.

\begin{tabular}{|l|l|l|l|}
\hline & $\mathrm{N}$ & Mean & Std deviation \\
\hline Pre-test & 22 & $24.0 \%$ & $12.7 \%$ \\
\hline Post-test & 22 & $40.9 \%$ & $10.1 \%$ \\
\hline Normalized gain & 22 & $20.0 \%$ & $20.1 \%$ \\
\hline
\end{tabular}

\subsection{Examination results}

Examination results were converted from letter grades into numerical grades using the standard conversion: $\mathrm{A}=5, \mathrm{~B}=4, \mathrm{C}=3, \mathrm{D}=2, \mathrm{E}=1$, and $\mathrm{F}=0$, and the results of the fall 2014 cohort were compared to the results of the fall 2013 cohort (see Table 2). The average number grade for the fall 2014 cohort was 2.63, which was near identical to that of the previous fall 2013 cohort of 2.64 .

However, the instructor's subjective experience was that the fall 2013 cohort had been academically stronger than the fall 2014 cohort, and was thus actually pleased by the identical average examination result. In an attempt to validate this notion, examination results in another course taken by most of the students in the Dynamic Systems course were investigated. Almost all the students in the Dynamic Systems course had taken a course on Electrical Circuits the year before, which had remained unchanged between the two cohorts, i.e., the curriculum, the instructor, and the teaching methods had not changed. The examination results (see Table 2) yielded an average numerical grade of 3.96 for the fall 2013 cohort and 3.35 for the fall 2014 cohort, which is a rather significant difference in the average course grade. This appears to corroborate the instructor's experience of the marked difference between the cohorts, although it is not conclusive. (The significant difference in average course grades between the two courses is due to one marker being considered a 'kinder' marker.)

Table 2: Examination results for courses in Electrical Circuits and Dynamic Systems for 2013 cohort and 2014 cohort.

\begin{tabular}{|c|c|c|c|c|c|c|c|c|}
\hline \multirow{3}{*}{$\begin{array}{l}\text { Grade } \\
\text { A }\end{array}$} & \multicolumn{4}{|c|}{ Fall 2013 cohort } & \multicolumn{4}{|c|}{ Fall 2014 cohort } \\
\hline & \multicolumn{2}{|c|}{ Electrical Circuits } & \multicolumn{2}{|c|}{ Dynamic Systems } & \multicolumn{2}{|c|}{ Electrical Circuits } & \multicolumn{2}{|c|}{ Dynamic Systems } \\
\hline & 20 & $38 \%$ & 6 & $10 \%$ & 9 & $21 \%$ & 3 & $6 \%$ \\
\hline B & 19 & $37 \%$ & 11 & $19 \%$ & 11 & $26 \%$ & 8 & $17 \%$ \\
\hline $\mathrm{C}$ & 8 & $15 \%$ & 16 & $28 \%$ & 14 & $33 \%$ & 21 & $44 \%$ \\
\hline $\mathrm{D}$ & 1 & $2 \%$ & 10 & $17 \%$ & 4 & $9 \%$ & 7 & $15 \%$ \\
\hline $\mathrm{E}$ & 3 & $6 \%$ & 11 & $19 \%$ & 5 & $12 \%$ & 2 & $4 \%$ \\
\hline $\mathrm{F}$ & 1 & $2 \%$ & 4 & $7 \%$ & 0 & $0 \%$ & 7 & $15 \%$ \\
\hline total & 52 & $100 \%$ & 58 & $100 \%$ & 43 & $100 \%$ & 48 & $100 \%$ \\
\hline
\end{tabular}




\subsection{Course evaluation}

The Dynamic Systems course was evaluated twice by the students during the fall semester 2014. The midterm evaluation was answered by 20 students $(41 \%)$ and the end evaluation by 12 students (24\%). When asked in the end-of-semester evaluation about active learning methods vs. traditional teaching, 55\% considered the active learning methods in Prolab better than traditional teaching methods, $15 \%$ were neutral and 30\% disagreed. Students commented that "the learning assistants are doing a great job", "theory questions in groups are good", "good learning outcome of the (ProLab) sessions", and "mini-tests are very useful to monitor studyprogress", which indicate that the changes made to the course based on the course evaluation of fall 2013 were successful. However, students had some good suggestions for further improvements, such as "use an anonymous reporting tool for mini-test results", work on a "better integration between theory and laboratory", "use mandatory mini-tests instead of mandatory homework", "highlight the importance of preparation and pre-lecture quizzes at the beginning of the semester", and "change the course book with the instructor's own compendium", thus clearly giving the instructor their vote of confidence.

\section{Summary of results}

In summary, a student attendance of $72 \%$ was considered good and above average among this student cohort. That the students were motivated to come to class was corroborated by the feedback in the course evaluation at the end of the semester, where the majority of those who responded indicated that they preferred the active learning classroom to traditional lecturing, and students emphasized the good learning outcome of the group work in ProLab.

There was also a clear improvement in students' conceptual understanding of control systems as measured by the Control Systems Concept Inventory. The students' improvement was similar to a comparable group of students tested by the designers of the Concept Inventory even though the Dynamic Systems course had only covered $72 \%$ of the material tested by the Concept Inventory.

However, it is the final examination that sheds most light on the impact ProLab may have had on student learning. Due to a pre-existing academic difference between the 2013 and 2014 cohorts, a direct comparison between these groups' examination results was not representative. However, most students in both cohorts had also taken a course in Electrical Circuits in their first year, a course that had not undergone any changes for the cohorts. The 2013 cohort outperformed the 2014 cohort in the Electrical Circuits course by two thirds of an entire letter grade on average, whereas they achieved identical average grades in the Dynamic Systems course. Although not conclusive, these results indicate that ProLab provided a better learning space than the previous year's traditional classroom.

\section{Conclusion}

We set out with three distinctly different research questions, the first of which was how to approach constructing the first Active Learning Classroom (ALC) in our tertiary institution. Our experience was that using the Pedagogy-Space-Technology Framework developed by Radcliffe et al. [16] was very helpful in guiding the process of designing and developing ProLab into a learning space that functioned according to our intentions. The second research question was how to approach teaching an engineering course in an ALC when the instructor had no personal experience of active learning methods or the education research such teaching methods are based on. Working with a pedagogical supervisor who had extensive experience of ALCs and knowledge of relevant research was valuable and sufficient support for an instructor who was motivated to change her teaching style. By the end of the course, the instructor had become 
comfortable with teaching in ProLab and had acquired competence and confidence that enabled her to further develop the use of ProLab for the Dynamic Systems course. Our last goal was to investigate whether we could see a positive effect on student performance after the first ALC trial. Although the results were not conclusive, a comparison of examination results with the previous year's cohort, attempting to correct for different levels of prior academic performance, indicate that ProLab was more valuable for student learning than the previous traditionally taught course. With the positive results from this first implementation of an ALC at our institution, there is no doubt that we will continue using ProLab for the Dynamic Systems course, while continuing to improve it, particularly by addressing and integrating useful student feedback.

\section{Acknowledgements}

The research work was funded by Oslo and Akershus University College, Faculty of Technology, Art and Design. Acknowledgements are also given to the student assistants, Silje Agnes Grøslie Wennesland and Eivind Vangen, for their dedication and positive contribution to the active learning environment at ProLab.

\section{Literature references}

1. $\quad$ Fraser, J.M., et al. Teaching and physics education research: bridging the gap. Reports on Progress in Physics, 2014. 77, 17 DOI: 10.1088/0034-4885/77/3/032401.

2. Freeman, S., et al. Active learning increases student performance in science, engineering, and mathematics. Proceedings of the National Academy of Sciences of the United States of America (PNAS), 2014. 6 DOI: 10.1073/pnas.1319030111

3. Hake, R.R., Interactive-engagement versus traditional methods: A six-thousandstudent survey of mechanics test data for introductory physics courses. Americal Journal of Physics, 1998. 66: p. 64-74.

4. Beichner, R.J., et al., The Student-Centered Activities for Large Enrollment Undergraduate Programs (SCALE-UP) Project, in Research-Based Reform of University Physics, E.F. Redish and P.J. Cooney, Editors. 2007, American Association of Physics Teachers: College Park.

5. Dori, Y.J. and J. Belcher, How Does Technology-Enabled Active Learning Affect Undergraduate Students' Understanding of Electromagnetism Concepts? The journal of the learning sciences, 2005. 14(2): p. 243-279.

6. Shieh, R.S., W. Chang, and E.Z.-F. Liu, Technology enabled active learning (TEAL) in introductory physics: Impact on genders and achievement levels. Australasian Journal of Educational Technology, 2011. 27(7): p. 1082-1099.

7. Bergmann, J. and A. Sams, Flip Your Classroom: Reach Every Student in Every Class Every Day. 2012: International Society for Technology in Education.

8. Novak, G., et al., Just-In-Time Teaching: Blending Active Learning with Web Technology. 1999, Upper Saddle River, NJ: Prentice Hall.

9. Lasry, N., E. Charles, and C. Whittaker When teacher-centered instructors are assigned to student-centered classrooms. Physical review special topics - Physical Education Research, 2014. 10, 9 DOI: 10.1103/PhysRevSTPER.10.010116.

10. Walker, J.D., D.C. Brooks, and P. Baepler, Pedagogy and Space: Empirical Research on New Learning Environments. EDUCAUSE Quarterly, 2011. 34(4).

11. Temple, P., Learning spaces for the 21 st century - A review of the literature. 2007, University of London: London. p. 84.

12. Cotner, S., et al., It's Not You, It's the Room"-Are the High-Tech, Active LearningClassrooms Worth It? Journal of College Science, 2013: p. 1-7. 
13. Radcliffe, D. A pedagogy-space-technology (PST) framework for designing and evaluating learning places. in Learning spaces in higher education: Positive Outcomes by Design 2008. St Lucia: University of Queensland.

14. Gaffney, J.D.H., et al., Scaling Up Education Reform. Journal of college science teaching, 2008. 37(5): p. 18-23.

15. Belcher, J., P. Dourmashkin, and D. Lister. TEAL Technology-Enhanced Active Learning. 2014 12.10.2014]; Available from: http://web.mit.edu/edtech/casestudies/teal.html.

16. Radcliffe, D., et al., Designing next generation places of learning: collaboration at the Pedagogy-Space-Technology nexus, U.o. Queensland, Editor. 2008, Australian Learning and Teaching Council: St Lucia. p. 20.

17. Bristow, M., et al., A Control Systems Concept Inventory Test Design and Assessment. IEEE Transactions on Education, 2012. 55(2): p. 10. 